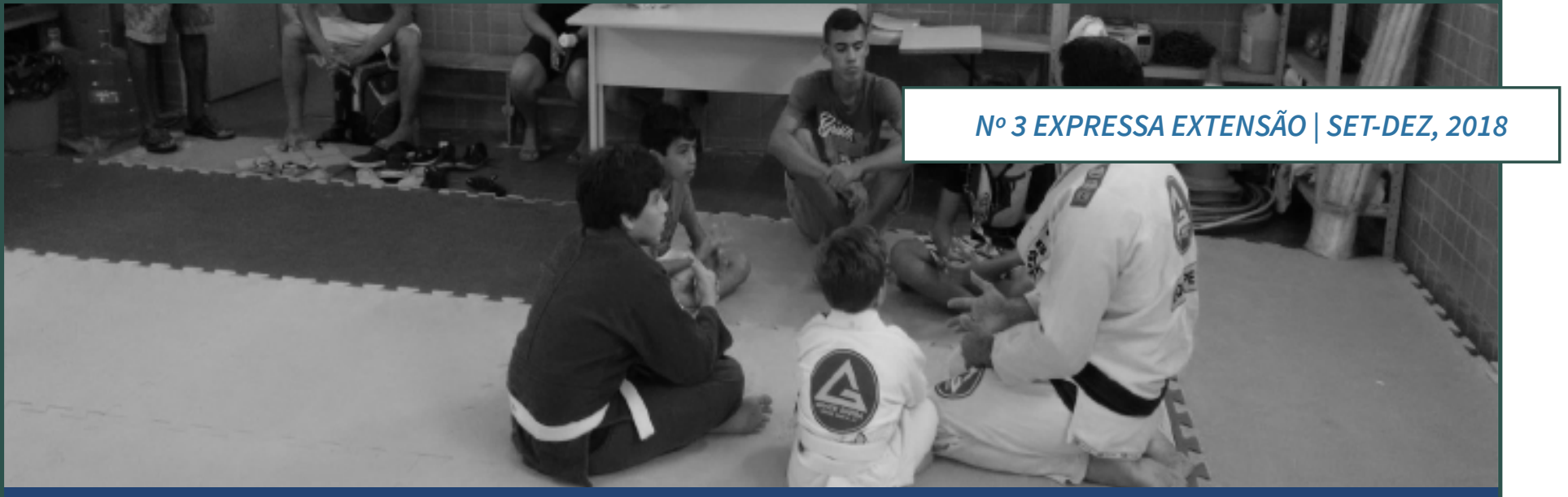

\title{
O JIU JITSU COMO PRÁTICA EDUCATIVA PARA A CIDADANIA INFANTO-JUVENIL
}

JIU JITSU AS EDUCATIONAL PRACTICE FOR CHILDREN-YOUTH CITIZENSHIP

Ahiram Brunni Cartaxo de Castro ${ }^{1}$ Kize Arachelli de Lira Silva ${ }^{2}$

Jedídja Hadassa de Santana Varela ${ }^{3} \quad$ Irma Lúcia da Silveira Silva $^{4} \quad$ Francisco Antonio de Pontes ${ }^{5}$

\section{RESUMO}

Este trabalho é fruto de um projeto de extensão desenvolvido no Campus Natal Central do Instituto Federal do Rio Grande do Norte (IFRN), no período de junho de 2016 a junho de 2017. Destaca-se como objetivos promover e sensibilizar crianças, adolescentes e jovens por meio do Jiu Jitsu brasileiro como uma prática educativa crítico-emancipatória de inclusão social para a cidadania. O Jiu Jitsu foi utilizado como um atrativo para o processo de aprendizagem social, pois foi a estratégia de aproximação do público infanto-juvenil para, por meio do processo crítico-emancipatório propostos por Elenor Kunz, ensinar e aprender temáticas para a construção de uma consciência cidadã em temas como: filosofia do Jiu Jitsu com ênfase em ensinamentos para a vida, a disciplina e os valores morais da sociedade; juventudes (drogas e comportamento na sociedade) e bullying na escola. Utilizou-se de aulas expositivas dialogadas e práticas de Jiu Jitsu, exercícios voltados para o aprendizado motor, exercícios táticos e recreativos. Também se empregou técnicas de demonstração e simulação. No caso das temáticas de cidadania, utilizou-se da auto-explicação ou da interrogação elaborativa. Os re-

${ }^{1}$ Instituto Federal de Educação, Ciência e Tecnologia do Rio Grande do Norte e Universidade Potiguar - Brasil Doutorando e Mestre em Administração, especialista em Gestão de Pessoas. Graduado em Administração. Administrador - brunnicastro@hotmail.com; 2Universidade Federal do Rio Grande do Norte - Brasil - Doutora e Mestra em Educação. Graduada em Pedagogia - kizearachelli@yahoo.com.br; ${ }^{3}$ Universidade Federal do Rio Grande do Norte - Brasil - Especialista em Psicologia Organizacional e do Trabalho e em Terapia Cognitivo Comportamental. Graduada em Psicologia - jhadassa2@gmail.com; ${ }^{4}$ nnstituto Federal de Educação, Ciência e Tecnologia do Rio Grande do Norte - Brasil - Mestre em Saúde Coletiva e graduada em Enfermagem. Especialista em Gestão Ambiental - irma.silva@ifrn.edu.br; ${ }^{5}$ Instituto Federal de Educação, Ciência e Tecnologia do Rio Grande do Norte - Brasil - Graduado em Contabilidade e Técnico-Administrativo em Educação - francisco.pontes@ifrn.edu.br 
sultados sinalizam que o Jiu Jitsu brasileiro pode ser utilizado como uma prática educativa crítico-emancipatória, que contribui para a construção da cidadania infanto-juvenil devido à sua competência objetiva (educacional), competência social (cidadania, comportamento social) e competência comunicativa (integração social e conhecimento corporal).

Palavras-chave: Jiu Jitsu. Prática educativa. Abordagem crítico-emancipatória. Cidadania. Juventude.

\section{ABSTRACT}

This work is the result of an extension project developed at the Campus Natal Central of the Federal Institute of Rio Grande do Norte (FIRN), from June 2016 to June 2017. It is highlighted the objectives of promoting and sensitizing children, adolescents and young people through Brazilian Jiu-Jitsu as a critical-emancipatory educational practice of social inclusion for citizenship. Jiu Jitsu was used as an attraction for the social learning process, as it was the strategy of approaching the child and youth audience, through the critical-emancipatory process proposed by Elenor Kunz, to teach and learn themes for the construction of a conscience citizen in subjects like: philosophy of Jiu Jitsu with emphasis in teachings for the life, the discipline and the moral values of the society; youth (drugs and behavior in society) and bullying in school. We used Jiu-Jitsu dialogues and practices, exercises focused on motor learning, tactical and recreational exercises. Demonstration and simulation techniques were also used. In the case of citizenship, self-explanatory or elaborative questioning was used. The results indicate that Brazilian Jiu-Jitsu can be used as a critical-emancipatory educational practice that contributes to the construction of children and youth citizenship due to their objective (educational) competence, social competence (citizenship, social behavior) and communicative competence (social integration and body knowledge).

Keywords: Jiu Jitsu. Educational practice. Critical-emancipatory approach. Citizenship. Youth.

\section{INTRODUÇÃO}

O Jiu Jitsu é um esporte que tem como base a alavanca, e tem experimentado um aumento constante de popularidade (ARRUDA; SOUZA, 2014), figurando, atualmente, como um fenômeno sociocultural (DA COSTA, 2006; BARROSO; DARIDO, 2006), pois "academias, competições organizadas e divulgação na mídia tornaram o esporte conhecido e acessível” (ARRUDA; SOUZA, 2014, p. 67). 
Toda prática esportiva, segundo Tubino (2002), pode representar-se por três manifestações básicas: "esporte-educação”, que tem como meta o caráter formativo concernente à educação para a saúde e para a cidadania, pois através de uma perspectiva lúdica enfatiza atitudes e comportamentos positivos que podem auxiliar na construção de hábitos saudáveis nas pessoas; "esporte-participação", na qual suas finalidades são o bem-estar e a participação do praticante, que desenvolve habilidades sociais direcionadas para a inclusão social, preparação de crianças, adolescentes e jovens para participarem de competições locais, melhora das funções orgânicas, promovendo saúde e reduzindo os riscos de desenvolvimento de doenças crônicas; e "esporte-performance", que objetiva o rendimento dentro de uma obediência rígida às regras e aos códigos existentes para cada modalidade esportiva, evidenciando-se o respeito ao próximo, a disciplina, a empatia, entre outros comportamentos.

A prática do Jiu Jitsu, nesse contexto, por ser complexa no sentido de exigir dos praticantes uma performance técnica e tática fina, desenvolve, ainda, a criatividade rápida ligada ao movimento, a ação ou a decisão, além da disciplina em seus praticantes (NEUENFELDT et al., 2013; RUFINO, 2012; JONES; LEDFORD, 2012).

Consoante a esse pensamento, ainda é possível constatar que, se por um lado o Jiu Jitsu brasileiro está crescendo em número de praticantes, visibilidade e popularidade (ANDREATO et al., 2015), por outro, também é comum encontrar reportagens veiculadas na mídia nas quais esse esporte admite conotações pejorativas ou que representam uma visão limitada sobre a modalidade, sendo muito comum a vinculação da imagem do Jiu Jitsu brasileiro a brigas, confusões e agressões (RUFINO; MARTINS, 2011; REIS; SUZUKI; GOMES, 2010). Como exemplo dessas distorções interpretativas, pode-se destacar manchetes jornalísticas nas quais se evidenciam esses entendimentos enviesados: "Lutador de jiu jitsu é acusado de matar travesti e queimar corpo" (O ESTADO DE SÃO PAULO, 2016); "Lutador de jiu-jitsu é preso no RJ por suspeita de assassinar a mulher" (GIRJ, 2016); "Lutador de jiu-jitsu é preso suspeito de agredir aposentado a socos em MS" (GIMS, 2016), entre outras.

Portanto, segundo Alvarez e Marques (2013), Vasques (2013) e Rufino e Martins (2011), a imagem do Jiu Jitsu brasileiro oscila, pois, em um extremo, há o aumento da popularidade e do conhecimento sobre a modalidade; em outro, o preconceito gerado pela falta de informação ou pela vinculação tendenciosa do Jiu Jitsu como esporte violento.

Dentro desse contexto dicotômico no qual o Jiu Jitsu brasileiro está envolvido, surge a seguinte indagação: o Jiu Jitsu brasileiro pode ser utilizado como 
uma prática educativa que poderá contribuir para a construção da cidadania de crianças, adolescentes e jovens?

A partir dessa questão, foi planejado e executado o projeto "O Jiu Jitsu como prática educativa para a cidadania infanto-juvenil", desenvolvido pelo Campus Natal Central do Instituto Federal de Educação, Ciência e Tecnologia do Rio Grande do Norte (IFRN), com o suporte do Programa de Apoio Institucional à Extensão do IFRN e com base na diretriz estratégica institucional de articular a escola e a comunidade como forma de ampliação e vivência do espaço público. Destaca-se como objetivo principal do projeto promover o referido esporte a partir da sensibilização de crianças, adolescentes e jovens, como uma prática educativa crítico-emancipatória de inclusão social para a cidadania.

No contexto dessa proposta, o Jiu Jitsu foi utilizado como um atrativo para o processo de aprendizagem social, utilizando estratégias para aproximar o público infanto-juvenil e, através do processo de dinâmica relacional, ensinar e aprender temáticas voltadas para construção de uma consciência cidadã, tais como: filosofia do Jiu Jitsu e de vida, disciplina e valores morais da sociedade, juventudes (drogas e comportamento na sociedade) e bullying na escola. Consideramos que essa intenção possibilita ampliar a visibilidade e o status positivo do Jiu Jitsu em Natal/RN, direcionando-se para a construção de uma consciência crítico-problematizadora em torno de temáticas relacionadas à convivência cidadã na sociedade em crianças, adolescentes e jovens em idade escolar, além de incluí-los socialmente, sendo esta, sua justificativa social.

O projeto também admite relevância pela possibilidade de envolver alunos do IFRN na prática da Iniciação Científica - como bolsistas -, bem como pela sua característica de indissociabilidade entre ensino, pesquisa e extensão, caracterizada pela integração da ação desenvolvida à formação cidadã dos beneficiários.

O quadro de análise do projeto se insere na perspectiva da abordagem crítico-emancipatória, conforme ensina Kunz (2003). Segundo essa autora, a abordagem supracitada se caracteriza, necessariamente, por uma didática comunicativa, baseada na função do esclarecimento e da prevalência racional de todo agir educacional.

Nesse contexto, o aluno, considerado como sujeito dos processos de ensino e de aprendizagem, deve ser capacitado para sua participação na vida social, política, cultural e esportiva, o que significa a aquisição de capacidades de ação funcional agregadas, também, às de reconhecer e problematizar sentidos e significados nesta vida através da percepção da causa, da sensibilização e da 
reflexão. Baseados nessa abordagem crítico-emancipatória, foram desenvolvidas três competências, quais sejam: a objetiva, a social e a comunicativa.

A competência objetiva diz respeito à construção do conhecimento efetivado pelo aluno no decurso da execução do Projeto, relacionando-se ao exercício de destrezas e diferentes técnicas que sejam racionais e eficientes, além da aprendizagem de estratégias capazes de pautar, com competência, suas ações (KUNZ, 2003).

Na competência social, o aluno deve compreender as diferentes relações que as pessoas têm na sociedade, sejam sociais, culturais ou históricas. Também deve compreender os problemas que as norteiam e as contradições do contexto social ao seu redor (KUNZ, 2003). Trata-se, nesses termos, de estabelecer conhecimentos que o aluno irá mobilizar em sua vida comunitária.

Já a competência comunicativa abarca a dimensão interacional, que se faz imprescindível, nesse contexto, por permitir/facilitar o ensinar e o aprender ou o comunicar e o entender o que o outro quer dizer. É um processo de reflexão que desencadeia a ação por meio de um pensamento crítico (KUNZ, 2003). Para a competência comunicativa, a linguagem verbal é muito importante, assim como a linguagem corporal. No entanto, nessa abordagem, a linguagem verbal é vista como um processo que vai auxiliar o aluno a ir além da identificação dos problemas e fatos que o rodeiam para torná-lo competente no discurso. Em outras palavras, na competência comunicativa, o aluno terá a possibilidade de suscitar reflexão e discutir as questões sobre o que está sendo abordado pelo professor. Essa abordagem é defendida por Kunz (2003) por permitir o desenvolvimento da compreensão das razões que balizam valores e hábitos institucionalizados na sociedade e que formam as convicções, as possibilidades e os limites de atuação dos sujeitos.

Isso posto, apresentamos, a seguir, os procedimentos metodológicos viabilizadores da condução do Projeto "O Jiu Jitsu como prática educativa para a cidadania infanto-juvenil", de modo que a atividade extensionista em pauta possa ser compreendida em sua plena execução.

\section{PROCEDIMENTOS METODOLÓGICOS}

Para a consolidação do projeto, atuaram na equipe três professores voluntários do Jiu Jitsu brasileiro - convidados pela equipe de coordenação -, um profissional da área da administração e um da área da saúde, além de outros membros para suporte administrativo, pedagógico e planejamento das ações. A equipe coordenadora manteve disponibilidade de quatro horas semanais em todo o período de execução do projeto em tela. 
A proposta extensionista já mencionada previa a participação de até 30 crianças/adolescentes/jovens em idade escolar da cidade de Natal/RN. A duração das aulas do projeto foi de doze meses, realizadas no período de junho de 2016 a junho de 2017 e organizadas em três ou dois encontros semanais de duas horas cada, totalizando 288 horas de aulas cumpridas no tatame de judô do campus Natal Central do IFRN.

Conforme o planejamento, cada aula era composta de esclarecimentos sobre a prática do Jiu Jitsu, alongamentos, exercícios voltados para o aprendizado motor, bem como exercícios táticos e recreativos para interação social dos alunos. Cada conteúdo do Jiu Jitsu foi trabalhado com variações e competições características de cada fundamento. Nesse sentido, foi possível trabalhar o afetivo-social dos alunos, o cognitivo, o tático e as habilidades motoras, buscando-se o desenvolvimento das competências social e comunicativa, conforme ilustra o Quadro 1.

Quadro 1 - Trechos do Plano de aula do Projeto "O Jiu Jitsu como prática educativa para a cidadania infanto-juvenil"

- História do Jiu Jitsu

\section{Conteúdos}

- Ensinamentos iniciais do Jiu Jitsu

- Contato inicial com o esporte (projeções [quedas], torções, pressões, imobilizações, desequilíbrios, inversões no solo etc). Cada um desses fundamentos será trabalhado em várias aulas, com variações e competições características de cada fundamento.

\section{Aquecimento (20 min)}

Procedimentos Metodológicos básicos para todas as aulas

\section{O gato e o rato:}

Os alunos fazem uma roda de mãos dadas. Dois jogadores ficam de fora da roda: um é o gato e o outro é o rato. Nesse caso, os alunos da roda começam a girar em sentido horário. Nesse momento, o aluno que será o gato tentará pegar o aluno que é o rato correndo ao redor da roda. Em um momento, o professor dará um sinal e os alunos da roda levantam os braços e o rato poderá entrar na toca que será o espaço entre um colega e outro com os braços levantados. O gato também poderá entrar na toca perseguindo o rato a fim de pegá-lo. O gato só pode entrar e sair da toca pelos lugares por onde passou o rato. O jogo termina quando o gato apanha o rato ou desiste, escolhendo-se um novo gato e um novo rato.

Abdominais, flexão, agachamentos, corrida moderada, pé de chinelo e alongamentos diversos.

Aula propriamente dita: orientações básicas (15 $\mathrm{min})$ :

- Amarrando a faixa:

Os alunos deverão dobrar a faixa ao meio, centralizando-a na cintura. Deverão passar as duas pontas pelas costas: uma ponta deverá passar por cima da outra, a ponta que ficar por cima deverá, agora, passar por baixo da amarração, a mesma ponta deverá passar por cima e por baixo da outra e é só apertar o nó.

- Desatar o laço:

Alunos divididos em dois grupos deverão amarrar, em volta da cintura, uma corda com um nó tipo laço. Cada aluno, de cada grupo, falará um número e o guardará na memória. Serão propostas áreas para o "combate". Ao comando do professor, que irá falar um número, os alunos correspondentes a este irão para a área de combate e tentarão tirar a corda um do outro. Ao final, o grupo que conseguir tirar mais cordas do adversário ganha o combate. - Amortecendo a queda: 
Os alunos deverão deitar no chão e fazer uma impulsão com as pernas para cima. Quando atingirem o ápice do movimento, deverão bater com as mãos no solo e retornar, ficando sentados no chão, lembrando sempre de manter o queixo no peito para a proteção. Um desafio será proposto e os alunos deverão tentar finalizar o amortecimento ficando de cócoras com as mãos na frente do corpo, realizando um nível maior do amortecimento.

- Orientações disciplinares:

Regras de respeito ao professor e aos colegas. Orientações sobre a reverência ao tatame.

Regras de convivência para o andamento das aulas e sobre a pontuação do Jiu Jitsu.

Aula propriamente dita: orientações específicas (35 $\mathrm{min}$ ):

$1^{\circ}$ e $2^{\circ}$ meses: postura defensiva, simulação de pegada, finalização e raspagem.

$3^{\circ}$ e $4^{\circ}$ meses: defesa de golpe de finalização, contragolpe e sair de baixo. Conceitos, história da técnica, parâmetros e informações adicionais (áreas de suporte didático). Verificação de dúvidas/questionar/induzir a participação no passo a passo e prática/drills/condicionamento (dificuldade progressiva, feedback do parceiro).

$5^{\circ}$ e $6^{\circ}$ meses: passagem de guarda, montada e pegar as costas. Conceitos, história da técnica, parâmetros e informações adicionais (áreas de suporte didático) e verificação de dúvidas/ questionar/induzir a participação no passo a passo e prática/drills/condicionamento (dificuldade progressiva, feedback do parceiro).

$7^{\circ}$ e $8^{\circ}$ meses: imobilizar lateralmente, defesa pessoal e ataque com joelho na barriga. Conceitos, história da técnica, parâmetros e informações adicionais (áreas de suporte didático) e verificação de dúvidas/questionar/induzir a participação no passo a passo e prática/drills/ condicionamento (dificuldade progressiva, feedback do parceiro).

$9^{\circ}$ e $10^{\circ}$ meses: mês: definir estratégia competitiva, execução do movimento da técnica em tempo real enfatizando a energia adequada em função da relação de "ação x reação" e demonstração do movimento da técnica passo a passo (ênfase em pegada, distribuição do peso, base, pontos de controle e transições). Conceitos, história da técnica, parâmetros e informações adicionais (áreas de suporte didático) e verificação de dúvidas/questionar/induzir a participação no passo a passo e prática/drills/condicionamento (dificuldade progressiva, feedback do parceiro).

$11^{\circ}$ e $12^{\circ}$ mês: Estudo de possíveis reações, suas respectivas soluções e observações de alunos, segunda prática/drills/condicionamento (mudando de parceiros ou não) e estímulo à criatividade - futuras inovações e adaptações a condições particulares.

Fonte: Elaboração dos autores (2018).

Concomitantemente às aulas de Jiu Jitsu, palestras foram planejadas visando-se ao desenvolvimento socioeducativo e à competência objetiva dos alunos em temas sobre: doenças sexualmente transmissíveis, gestão das finanças pessoais, desenvolvimento de equipes, habilidades sociais, ética, valores morais na sociedade etc. A sequência de trabalho e as técnicas planejadas pela equipe do projeto envolviam as seguintes atividades:

- Realização de abertura oficial do projeto com apresentação do calendário de execução das aulas de Jiu Jitsu e das palestras de cidadania (socioeducativas);

- Realização de reuniões de planejamento das ações com a equipe para a discussão dos critérios de seleção dos alunos em idade escolar. Realizou-se, sempre que necessário, encontros que se estenderam durante toda a execução do projeto, a fim de que a equipe, os alunos, os pais, os parceiros e os bolsistas participassem das avaliações e das decisões sobre o andamento e a melhoria contínua do projeto;

- Realização de 144 aulas práticas de Jiu Jitsu brasileiro combinadas com conteúdos de cidadania, utilizando-se de quadro ou prancheta, tatame, brin- 
cadeiras, dinâmicas de grupo e materiais tipo cordas, cones, quimono, faixas etc. As atividades foram realizadas prioritariamente em dupla ou em grupos, valorizando-se, com isso, o estímulo à cooperação entre os alunos. As sugestões de práticas deveriam ser levantadas juntamente com os alunos. $1^{\circ}$ e $2^{\circ}$ meses: aulas de Jiu Jitsu e aulas sobre Doenças Sexualmente Transmissíveis (DST's) e Sexualidade na Adolescência; $3^{\circ}$ e $4^{\circ}$ meses: aulas de Jiu Jitsu e aulas sobre empreendedorismo social; $5^{\circ}$ e $6^{\circ}$ meses: aulas de Jiu Jitsu e aulas sobre Gestão das Finanças Pessoais; $7^{\circ}$ e $8^{\circ}$ meses: aulas de Jiu Jitsu e aulas sobre Habilidades Sociais e Relacionamentos Afetivos; $9^{\circ}$ e $10^{\circ}$ meses: aulas de Jiu Jitsu e aulas sobre Ética e Valores Morais na sociedade e; $11^{\circ}$ e $12^{\circ}$ meses: aulas de Jiu Jitsu e aulas sobre Juventude e Drogadição.

- As avaliações foram realizadas ao fim de cada aula sobre a aprendizagem do conteúdo associado às aulas de Jiu Jitsu. Tomamos, como fundamento avaliativo do Jiu Jitsu, as situações nas quais os alunos simulavam a técnica ensinada, e para as temáticas de cidadania, utilizou-se o instrumento da autoexplicação (o aluno explicava com suas próprias palavras o que compreendeu) ou através da interrogação elaborativa (os professores interrogavam os alunos sobre explicações que justificassem os porquês de determinadas situações ocorridas durante as aulas, se eram verdadeiras ou falsas). Assim, os alunos iam construindo seus conhecimentos;

- Registro do desempenho da aprendizagem dos alunos ao final de cada aula de Jiu Jitsu e de cidadania;

- Certificação das turmas concluintes;

- Registro dos dados da avaliação de aprendizagem dos alunos referente aos conteúdos de Jiu Jitsu e de cidadania para fomentar publicação científica em revistas de extensão e em eventos científicos.

Destaque-se que o projeto, como prática educativa6, tinha como proposta alinhar-se ao proposto por Zabala (1998), quando este coloca que o critério para se estabelecer o nível de aprendizagem numa prática educativa refere-se às capacidades e aos conhecimentos prévios de cada aluno(a). Essa proposição marca, também, a forma de condução do processo. Do conjunto de relações necessárias para facilitar a aprendizagem, se atribuiu uma série de funções ao professor na condução de uma prática educativa, inclusive como facilitador no desenvolvimento das três competências apresentadas por Kunz (2003) junto aos alunos, conforme mostra o Quadro 2.

\footnotetext{
6"[...] a forma de condução do ensino de um determinado tema. Os objetivos utilizados para este fim, quais os envolvidos e como se dará sua participação (até mesmo em que a escala se dará) e quais os objetivos a serem alcançados são os elementos constitutivos da prática educativa. Na prática educativa, o professor tem um papel fundamental, ainda que ela não esteja centrada em suas ações, apenas dando pequenas orientações e fazendo observações. [...] Nesse processo, pode-se reconhecer na prática educativa a possibilidade da transgressão a partir das intenções do docente na mediação das interações entre o 'mundo físico e o social'". (BRAGANÇA; FERREIRA; PONTELO, 2015, p. 2).
} 
Quadro 2 - Funções do professor na condução de uma prática educativa

\begin{tabular}{|c|c|}
\hline Função do professor & Objetivo \\
\hline $\begin{array}{l}\text { Flexibilizar a atuação } \\
\text { docente }\end{array}$ & $\begin{array}{l}\text { Permitir adaptação às necessidades dos alunos em todo o proces- } \\
\text { so de ensino e de aprendizagem. }\end{array}$ \\
\hline $\begin{array}{l}\text { Regatar os } \\
\text { conhecimentos prévios } \\
\text { do aluno }\end{array}$ & $\begin{array}{l}\text { Contar com as contribuições e os conhecimentos dos alunos, tan- } \\
\text { to no início das atividades como durante sua realização. }\end{array}$ \\
\hline $\begin{array}{l}\text { Ajudar o aluno a } \\
\text { encontrar sentido }\end{array}$ & $\begin{array}{l}\text { Motivar o aluno a conhecer o que tem que fazer, perceber que } \\
\text { pode fazê-lo e que é interessante fazê-lo. }\end{array}$ \\
\hline Oferecer ajuda adequada & $\begin{array}{l}\text { Para que o aluno experimente progressos que se motive a enfren- } \\
\text { tar os obstáculos com os quais se depara. }\end{array}$ \\
\hline $\begin{array}{l}\text { Promover atividade } \\
\text { mental auto-estruturante }\end{array}$ & $\begin{array}{l}\text { Permitir o estabelecimento máximo de relações com novos con- } \\
\text { teúdos, atribuindo-lhes significado e favorecendo os processos de } \\
\text { meta-cognição que lhe permitam assegurar o controle pessoal } \\
\text { sobre os próprios conhecimentos e processos durante a apren- } \\
\text { dizagem. }\end{array}$ \\
\hline Criar ambiente favorável & $\begin{array}{l}\text { Estabelecer um ambiente e relações envolvidas em respeito } \\
\text { mútuo e sentimento de confiança, promovendo a autoestima e o } \\
\text { autoconceito. }\end{array}$ \\
\hline Comunicar & $\begin{array}{l}\text { Promover canais de comunicação que regulem os processos de } \\
\text { negociação, participação e construção. }\end{array}$ \\
\hline $\begin{array}{l}\text { Favorecer a autonomia } \\
\text { dos alunos de forma } \\
\text { progressiva }\end{array}$ & $\begin{array}{l}\text { Potencializar, progressivamente, a autonomia dos alunos na } \\
\text { definição de objetivos, no planejamento das ações que os condu- } \\
\text { zirão aos objetivos e em sua realização e controle, possibilitando } \\
\text { que aprendam a aprender. }\end{array}$ \\
\hline Avaliar os alunos & $\begin{array}{l}\text { Conforme suas capacidades e seus esforços, os alunos devem ser } \\
\text { avaliados levando-se em conta o ponto pessoal de partida e o } \\
\text { processo através do qual adquirem conhecimentos, incentivando } \\
\text { a autoavaliação das competências como meio para favorecer as } \\
\text { estratégias de controle e regulação da própria atividade. }\end{array}$ \\
\hline
\end{tabular}

Fonte: Adaptado de Zabala (1998).

Portanto, um dos focos pretendidos pela equipe do projeto centrou-se no processo de condução, o qual deveria ser mediado pelos professores voluntários. Por fim, esperava-se com o Projeto:

- Capacitar os bolsistas (membros do projeto) para compreenderem a relação interdisciplinar que pode existir entre áreas do conhecimento, tais como o esporte e a cidadania;

- Viabilizar uma maior integração entre a sociedade com o Campus Natal Central do IFRN como forma de fortalecer o processo de educação para a cidadania; melhoria da qualidade de vida e saúde dos beneficiários do projeto; e atingir os objetivos estratégico da instituição;

- Inserir os alunos participantes do projeto nos jogos escolares estaduais e municipais;

- Ampliar a visibilidade e o status positivo do Jiu Jitsu na cidade de Natal/ $\mathrm{RN}$;

- Publicar artigos sobre o projeto em revistas de extensão/livro, bem como 
publicação do trabalho em eventos científicos, a fim de que essa experiência possa servir de referência para outras ações similares em instituições de compromisso com o desenvolvimento da cidadania;

- Construir uma consciência para temáticas relacionadas à convivência cidadã na sociedade em crianças, adolescentes e jovens em idade escolar.

O projeto de extensão previa, ainda, avaliações contínuas no período de sua execução por meio de dinâmicas de feedback dos alunos, pais, professores voluntários e da equipe do projeto, sobre o desenvolvimento metodológico das aulas e das competências dos alunos, sobre a fixação dos conteúdos através das técnicas de simulação, auto explicação ou através da interrogação elaborativa. A cada aula realizada, também era previsto o registro do desempenho da aprendizagem dos alunos através de observação participante, registro fotográfico, registro de relato dos alunos sobre sua aprendizagem, registro de relato do professor colaborador e dos bolsistas envolvidos.

Além disso, o projeto ainda previa o acompanhamento da frequência dos alunos/beneficiários e proponentes do projeto como critério de certificação.

\section{RESULTADOS E DISCUSSÃO SOBRE A EXECUÇÃO DO PROJETO}

Considerando-se que o projeto representou uma prática educativa em movimento direcionada ao desenvolvimento de competências humanas, fundamentado na possibilidade de trazer mudanças comportamentais nos indivíduos, consideramos que a ação se constituiu como um processo formativo continuado de caráter intencionalmente planejado, com objetivos educacionais claramente explícitos, sistemáticos e delimitados, que passou por várias mudanças no seu transcorrer como forma de adaptação à realidade dos seus beneficiários.

No contexto de sua execução, a equipe do projeto precisou realizar adaptações no planejamento inicial após ter contato com as demandas dos alunos. Essas adaptações aconteceram na seguinte sequência:

- Reunião com os membros do projeto, na qual foi decidida a integração de crianças já selecionadas por um projeto social de futebol pré-existente no Campus Natal Central do IFRN, denominado Projeto Fraldinha ${ }^{7}$, visto que a equipe verificou, nas dependências deste campus, muitas crianças, adolescentes e jovens ociosos após seus treinamentos de futebol ou que eram filhos de alunos do Projeto Fraldinha, bem como devido à similaridade entre os objetivos dos projetos. As crianças eram convidadas ainda na lateral do campo de

\footnotetext{
${ }^{7}$ Visa à promoção de uma cultura de paz e de respeito aos direitos humanos, visando à redução da violência a partir da viabilização do acesso ao esporte, à cultura, à arte, à geração de renda e ao exercício pleno da cidadania para crianças e adolescentes carentes que estejam com seus direitos ameaçados ou violados, bem como para os seus familiares. (PROJETO FRALDINHA, 2016).
} 
futebol do Campus Natal Central do IFRN pelos professores e pelos membros da equipe do Projeto de Jiu Jitsu quando encerravam suas aulas ou enquanto transitavam nas dependências do campus;

- Reunião e pesquisa documental sobre o tema das palestras que foram convertidas em rodas de conversa e das aulas de Jiu Jitsu, por se tratar de uma técnica mais adequada para a realidade dos alunos e seus pais;

- Na primeira aula, realizada em 04 de junho de 2016, de abertura do projeto e acolhimento dos pais e alunos, houve uma roda de conversa sobre a filosofia do Jiu Jitsu e sua interação com a sociedade e a apresentação do projeto com seu cronograma, conforme a Figura 1. Nesse momento, houve o ajuste das temáticas e das técnicas a serem trabalhadas com os alunos e os pais, que, inclusive, demandaram atendimento psicológico:

Figura 1 - Acolhimento de alunos e pais com orientações sobre a filosofia do Jiu Jitsu

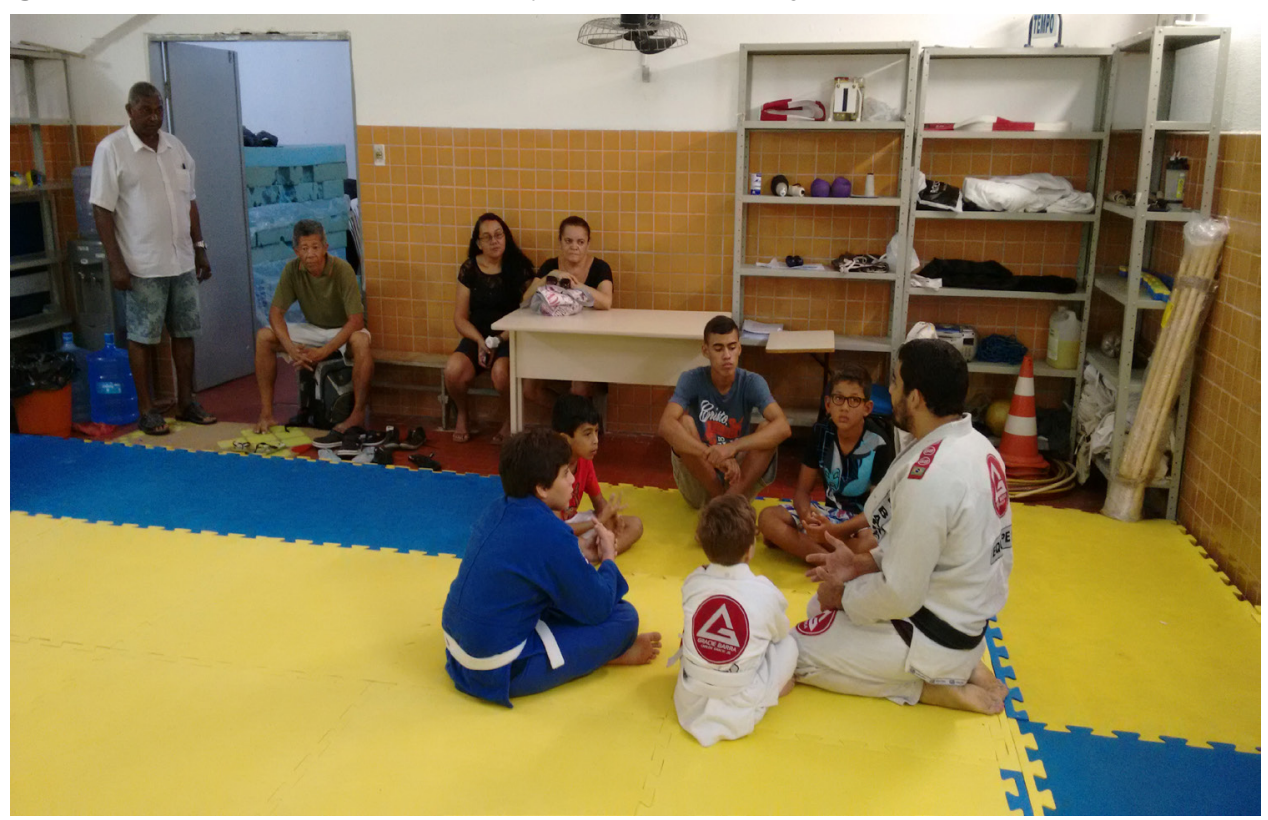

Fonte: Acervo fotográfico dos autores (2016).

- A equipe do projeto buscou conhecer outros projetos sociais e o trabalho de academias da cidade. Essa integração com outras academias possibilitou a construção de uma rede de relacionamentos com pessoas para viabilizar a doação dos quimonos e faixas para os alunos, pois o projeto não previa recursos financeiros para sua aquisição. Foram adquiridos, por doação junto às academias, nove quimonos, três faixas e mais um quimono para o projeto foi fruto do cachê de um dos professores por arbitrar uma competição regional. $A$ execução dessa campanha se deu através de redes sociais;

- Foram realizadas 144 aulas de Jiu Jitsu (cada uma com duas horas de duração), sendo três aulas por semana, vários momentos de conversa sobre cidadania conforme as temáticas por mês e quatro atendimentos psicológicos para os pais dos alunos (Fig. 2). As aulas foram realizadas nas terças e quintas-feiras e também aos sábados. As rodas de conversa foram realizadas com os seguintes temas respectivamente: $1^{\circ}$ e $2^{\circ}$ meses - Filosofia do Jiu Jitsu, 
disciplina e valores morais na sociedade; $3^{\circ}$ e $4^{\circ}$ meses - Juventude e Sociedade (Drogadição e comportamento na sociedade); $5^{\circ}$ e $6^{\circ}$ meses - Bullying na escola; $7^{\circ}$ e $8^{\circ}$ meses - Filosofia do Jiu Jitsu (mente e corpo); $8^{\circ}$ e $9^{\circ}$ meses - Convivência na sociedade e; $10^{\circ}$ e $11^{\circ}$ meses - Importância do Jiu Jitsu para a vida.

- Os atendimentos psicológicos foram realizados nos meses de agosto e setembro de 2016, por psicóloga voluntária convidada pela equipe do projeto, em dias de sábado enquanto os alunos tinham aula.

Figura 2 - Roda de conversa sobre Bullying na escola

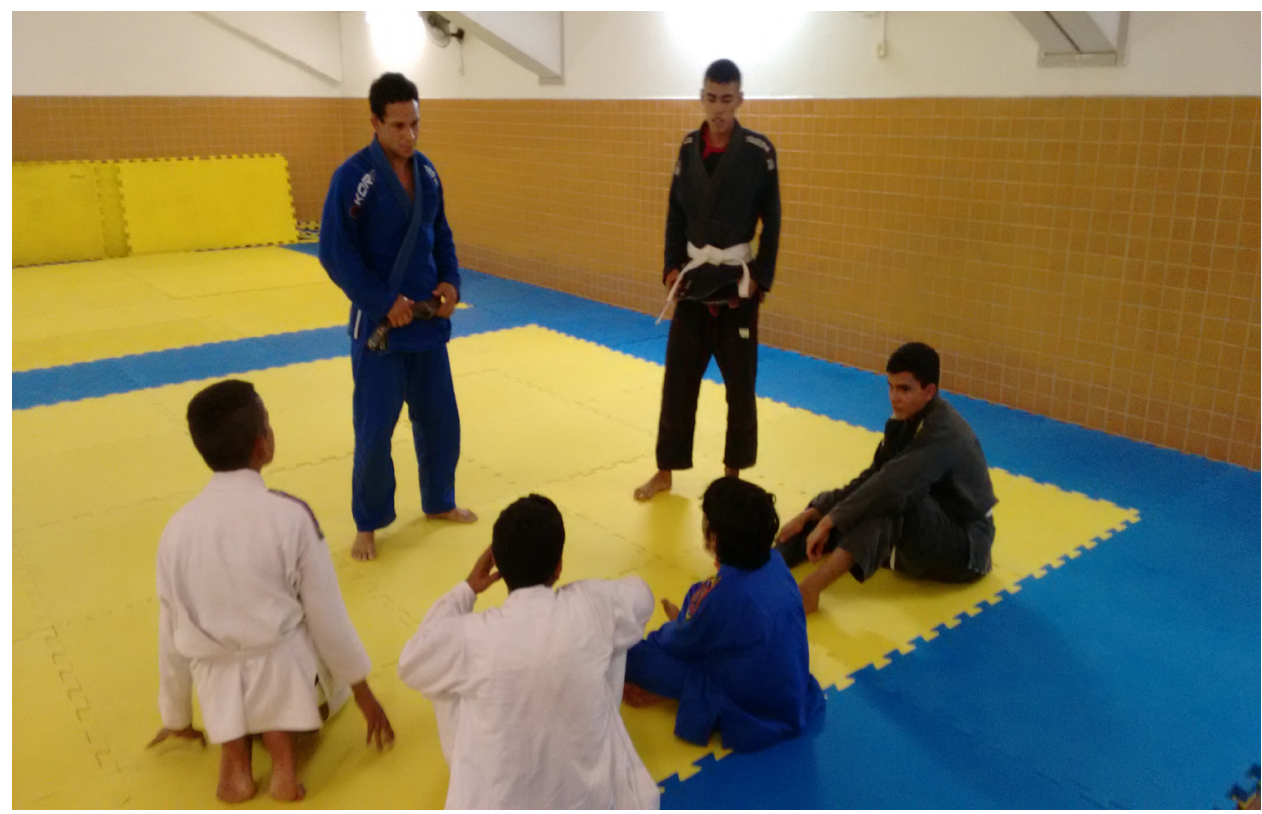

Fonte: Acervo fotográfico dos autores (2016).

- A avaliação dos alunos durante o projeto ocorreu através de simulações, auto explicação e interrogações elaborativas sobre golpes, raspagens, entradas, defesas, posturas, sobre o material (quimonos, faixas e tatame) e disciplina na família e na sociedade. Também foram aplicadas as mesmas técnicas relativas aos assuntos de cidadania tratados nas rodas de conversa com os alunos. O registro da aprendizagem dos alunos sobre participação e desenvolvimento da disciplina relativa ao esporte e da aprendizagem dos temas relacionadas à cidadania dos alunos, foram realizados a cada três meses de execução do projeto. No último mês do projeto, houve ainda a aplicação de uma entrevista com os alunos, professores voluntários, bolsista e pais dos alunos, quando se pretendia realizar um senso com todos os atores do projeto, entretanto, nem todos estavam presentes no período da coleta dos dados. Nesse caso, a amostra foi por conveniência. (KOTLER, 2000).

Participaram do projeto, vinte e dois alunos, com rotatividade, sendo vinte do sexo masculino e dois do sexo feminino, com idade média de 16 anos, com renda familiar média de 2,5 salários mínimos, residentes, em sua maioria, no bair- 
ro Nova Descoberta (circunvizinho ao Campus Natal Central do IFRN) e haviam ingressado no projeto através de convite dos professores.

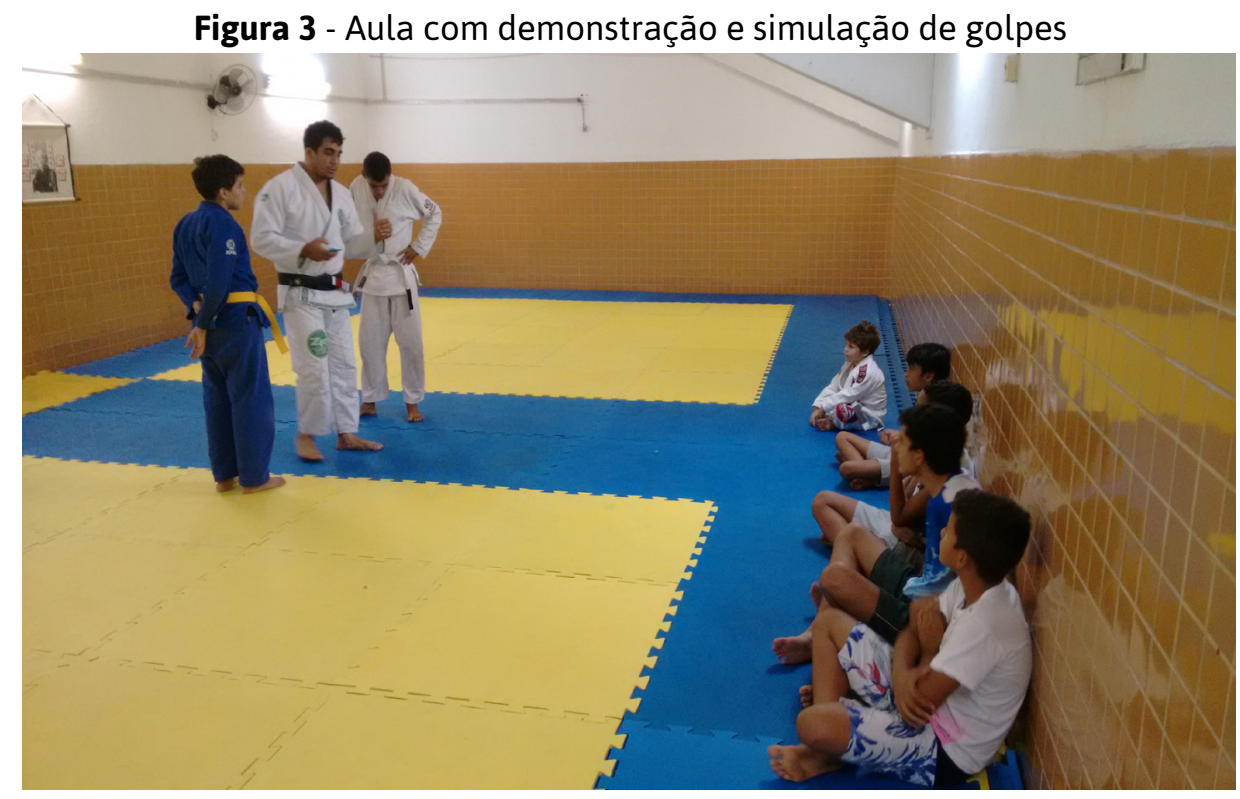

Fonte: Acervo fotográfico dos autores (2016).

Quando perguntados, no início do projeto, sobre qual a imagem que tinham do Jiu Jitsu, os alunos recorreram ao levantado por Rufino e Martins (2011); Reis, Suzuki e Gomes (2010), quando colocaram que a imagem do Jiu Jitsu ainda era vinculada a brigas, violência e agressões, conforme os relatos em seguida:

É um esporte violento, o pessoal utiliza para brigar nas ruas e entre as gangues. (A. A. A.);

É um esporte violento. (B. B. B.);

Violento. (C. C. C.).

Ao final do Projeto, os alunos foram novamente entrevistados pela equipe com o mesmo questionamento, atualizando-o apenas temporalmente: qual a imagem que você tem atualmente do Jiu Jitsu?

Esporte que melhora a saúde física. (A. A. A.)

Disciplina e respeito. (B. B. B.)

Melhora o condicionamento físico, a integração entre nós e a disciplina em casa. (C. C. C.)

É um esporte que ajuda na disciplina, na defesa pessoal e melhora a capacidade física. (D. D. D.).

Outras perguntas também foram dirigidas aos alunos com o objetivo de capturar o sentimento dos mesmos, recebendo um feedback positivo. 
Quadro 3 - Perguntas e resposta da entrevista com os alunos do Projeto "O Jiu Jitsu como prática educativa para a cidadania infanto-juvenil"

\begin{tabular}{|c|c|c|}
\hline Perguntas & Respostas & Competência \\
\hline $\begin{array}{l}\text { 1. Qual a importância } \\
\text { do projeto para você? }\end{array}$ & $\begin{array}{l}\text { “Melhoria de minha capacidade física”. (A. A. A.) } \\
\text { "Por causa do aprendizado”. (B. B. B.) } \\
\text { "Para ficar longe das drogas. Me deixa ocupado para } \\
\text { não me envolver com amizades ruins do morro". (C. C. } \\
\text { C.) } \\
\text { “Melhorou o meu condicionamento físico, minha visão } \\
\text { sobre o esporte e a minha disciplina”. (D. D. D.) }\end{array}$ & Comunicativa \\
\hline \multicolumn{3}{|c|}{ 2. QUAIS AS CONTRIBUIÇÕES DO JIU JITSU PARA SUA VIDA? } \\
\hline $\begin{array}{l}\text { 2.1. Quanto à edu- } \\
\text { cação (desenvolvi- } \\
\text { mento intelectual e } \\
\text { moral - cidadania do } \\
\text { ser humano)? }\end{array}$ & $\begin{array}{l}\text { "Trouxe mais disciplina e a compreensão da im- } \\
\text { portância do respeito com os colegas, professores e } \\
\text { na sociedade”. (A. A. A.) } \\
\text { “Me deu disciplina e autoconfiança”. (B. B. B.) } \\
\text { “Educação com disciplina”. (C. C. C.) } \\
\text { “Aprendi a ter mais respeito para com meus pais”. (D. } \\
\text { D. D.) } \\
\text { “O jiu jitsu me fez ver que há respeito entre adversári- } \\
\text { os e que me fez mudar muito o meu pensamento". (E. } \\
\text { E. E.) } \\
\text { “Disciplina”. (F. F. F.) }\end{array}$ & Objetiva \\
\hline $\begin{array}{l}\text { 2.2. Quanto à sociabil- } \\
\text { idade (capacidade de } \\
\text { integração com outras } \\
\text { pessoas)? }\end{array}$ & $\begin{array}{l}\text { “É bastante integrativo e dinâmico". (A. A. A.) } \\
\text { “O projeto me deu a oportunidade de aprender jiu } \\
\text { jitsu sem pagar, porque não posso”. (B. B. B.) } \\
\text { “Melhorou um pouco minha concentração”. (C. C. C.) } \\
\text { “Desde que o projeto começou, me tornei mais so- } \\
\text { ciável”. (D. D. D.) } \\
\text { “Melhorou minha comunicação”. (E. E. E.) }\end{array}$ & Social \\
\hline $\begin{array}{l}\text { 2.3. Quanto à discipli- } \\
\text { na na escola, família e } \\
\text { lugares sociais? }\end{array}$ & $\begin{array}{l}\text { “Me deu capacidade de maior disciplina, concen- } \\
\text { tração, para lhe dar com todos". (A. A. A.) } \\
\text { "Ser mais disciplinado". (B. B. B.) } \\
\text { “Mais respeito com as pessoas". (C. C. C.) } \\
\text { "Tenho uma noção melhor sobre o respeito com as } \\
\text { pessoas". (D. D. D.) } \\
\text { “Melhorou bastante a minha disciplina”. (E. E. E.) } \\
\text { “Melhorou o respeito as normas e aos mais experien- } \\
\text { tes". (F. F. F.) }\end{array}$ & Educacional \\
\hline $\begin{array}{l}\text { 2.4. Quanto à quali- } \\
\text { dade de vida (melho- } \\
\text { ria do condicionamen- } \\
\text { to físico, flexibilidade } \\
\text { etc.)? }\end{array}$ & $\begin{array}{l}\text { “Melhorou o condicionamento físico”. (A. A. A.) } \\
\text { “Antes de começar o projeto eu tinha pouca vontade } \\
\text { de praticar esportes, comia pouco; agora, estou com } \\
\text { mais vontade e passei a fazer outros esportes e me } \\
\text { alimento saudavelmente” (B. B. B.) }\end{array}$ & Comunicativa \\
\hline
\end{tabular}

Fonte: Elaboração dos autores (2018).

Quanto aos demais atores do projeto (professores, bolsista e pais), tem-se que o projeto também recebeu uma avaliação positiva. 
Quadro 4 - Entrevista com professores e bolsista do Projeto de Extensão "O Jiu Jitsu como prática educativa para a cidadania infanto-juvenil"

\begin{tabular}{|c|c|c|}
\hline Ator & Pergunta & Depoimento \\
\hline $\begin{array}{l}\text { Professor R. } \\
\text { P. P. }\end{array}$ & & $\begin{array}{l}\text { "As melhorias são perceptíveis visualmente, tem um dos } \\
\text { alunos inclusive que era muito tímido e hoje esta muito mais } \\
\text { autoconfiante para a vida, o jiu jitsu prepara para a vida. Pes- } \\
\text { soas que fazem artes maciais sentem mais segurança, provado } \\
\text { cientificamente inclusive para lhe dar com os problemas do } \\
\text { dia a dia. Além disso, o jiu jitsu melhorou muito o condicio- } \\
\text { namento dos alunos e nenhum aluno teve problemas, pois o } \\
\text { esporte é pouco lesivo para o corpo. É um esporte individual, } \\
\text { mas também é coletivo, os alunos precisam treinar em dup- } \\
\text { las no sentido de preservar o outro. Essa é uma das disciplinas } \\
\text { desenvolvidas. Resumindo o papel do jiu jitsu para os alunos } \\
\text { foi torna-los mais confiantes, com saúde do corpo e ter dis- } \\
\text { ciplina para lhe dar na sociedade, saber se comunicar, saber } \\
\text { respeitar... essa integração social que o jiu jitsu faz e que } \\
\text { proporcionou para os alunos tem os deixado mais sociáveis. }\end{array}$ \\
\hline $\begin{array}{l}\text { Professor D. } \\
\text { C. de M. B. }\end{array}$ & $\begin{array}{l}\text { cepção, qual a } \\
\text { evolução edu- } \\
\text { cacional (refer- } \\
\text { ente à discipli- } \\
\text { na dos alunos } \\
\text { e história do } \\
\text { Jiu Jitsu), física } \\
\text { (melhoria da } \\
\text { aptidão física, } \\
\text { performance) } \\
\text { e social (inte- } \\
\text { gração social } \\
\text { e inclusão so- } \\
\text { cial) visualiza- } \\
\text { da nos alunos? }\end{array}$ & $\begin{array}{l}\text { "Bom o Brazilian Jiu-Jitsu é uma arte marcial desenvolvida } \\
\text { para os mais fracos, Helio Graice um dos maiores e melhores } \\
\text { atletas do esporte representou bem essa teoria e isso ajudou a } \\
\text { mostrar a força que esse esporte tem. Por ser uma arte marcial } \\
\text { o Jiu-Jitsu tem toda uma filosofia que a envolve. Isso é possível } \\
\text { perceber no momento em que se veste o quimono e inicia-se } \\
\text { a primeira aula do aluno, neste projeto em especial podemos } \\
\text { perceber como se destacam os alunos ao entrarem no dojo re- } \\
\text { speitando o espaço o professor e os colegas de turma, rever- } \\
\text { enciando a todos como um ato de humildade e respeito. Essa } \\
\text { postura do atleta transforma sua concepção no momento em } \\
\text { que o professor reverencia juntamente e agradece sua pre- } \\
\text { sença, para o aluno essa demonstração de respeito gera em } \\
\text { contrapartida uma vontade de respeitar, já que a base da har- } \\
\text { monia de um ambiente coletivo é o respeito, com isso o atle- } \\
\text { ta se sentindo bem no tatame sente a necessidade de fazer o } \\
\text { mesmo em casa e na rua. Ele difunde o respeito em troca de } \\
\text { respeito. Por ser um esporte de contato o atleta leva a seus } \\
\text { limites sua forma física buscando e melhorando a cada treino } \\
\text { sua disposição e conhecimento de novos movimentos da arte, } \\
\text { a intensidade do treino é tanta que o corpo responde, de forma } \\
\text { cardiovascular, muscular, bem como liberação de hormônios } \\
\text { que estimulam a tranquilidade e serenidade do atleta. Social- } \\
\text { mente nós temos a oportunidade de estarmos ajudando mui- } \\
\text { tos que sofrem por injustiças e falta de oportunidades, o Jiu } \\
\text { Jitsu sempre forte se apresenta como uma ferramenta capaz } \\
\text { de elevar seus níveis de confiança e força de vontade, fazendo } \\
\text { com que os obstáculos da vida se tornem mais possíveis de } \\
\text { serem alcançados. Desistir não é uma opção! Esse ensinamen- } \\
\text { to carrego comigo e transmito aos meus alunos todos os dias". }\end{array}$ \\
\hline
\end{tabular}




\begin{tabular}{|l|l|l|l|}
\hline & $\begin{array}{l}\text { Referente ao } \\
\text { Projeto do qual } \\
\text { participa, qual }\end{array}$ & $\begin{array}{l}\text { "Quando o projeto começou, pensei que fosse apenas au- } \\
\text { las de como "lutar" jiu jitsu. Porém, no decorrer do proje- } \\
\text { to, fui aprendendo lições de vida com o professor e me dis- } \\
\text { ciplinando, pois sabia que não poderia utilizar de "golpes" } \\
\text { a sua com- } \\
\text { contra pessoas de fora do projeto e também tomei ciência } \\
\text { C. da S. }\end{array} \quad \begin{array}{lr}\text { preensão so- } \\
\text { bre a relação } \\
\text { entre esporte } \\
\text { e cidadania/in- } \\
\text { clusão social? }\end{array}$ & $\begin{array}{l}\text { projeto também foi uma ótima oportunidade para os alunos } \\
\text { que puderam aprender uma arte marcial capaz de incluí-los } \\
\text { socialmente na sociedade através do respeito as pessoas". }\end{array}$ \\
\hline
\end{tabular}

Fonte: Elaboração dos autores (2018).

Quanto aos pais, através da análise de frequência de seus discursos, percebeu-se a repetição de palavras-chaves que corroboram os objetivos do projeto, tais como: disciplina, obediência e respeito, caracterizando o desenvolvimento da manifestação "esporte-performance", conforme colocado por Tubino (2002), que objetiva o desenvolvimento do rendimento dentro de uma obediência rígida às regras e aos códigos existentes para cada modalidade esportiva, evidenciando-se o respeito ao próximo, a disciplina, a empatia, entre outras habilidades; bem como o desenvolvimento das competências objetiva (educacional) e social (cidadania e comportamento social).

Figura 4 - TagCrowd da análise de discurso por frequência das respostas dos pais dos alunos

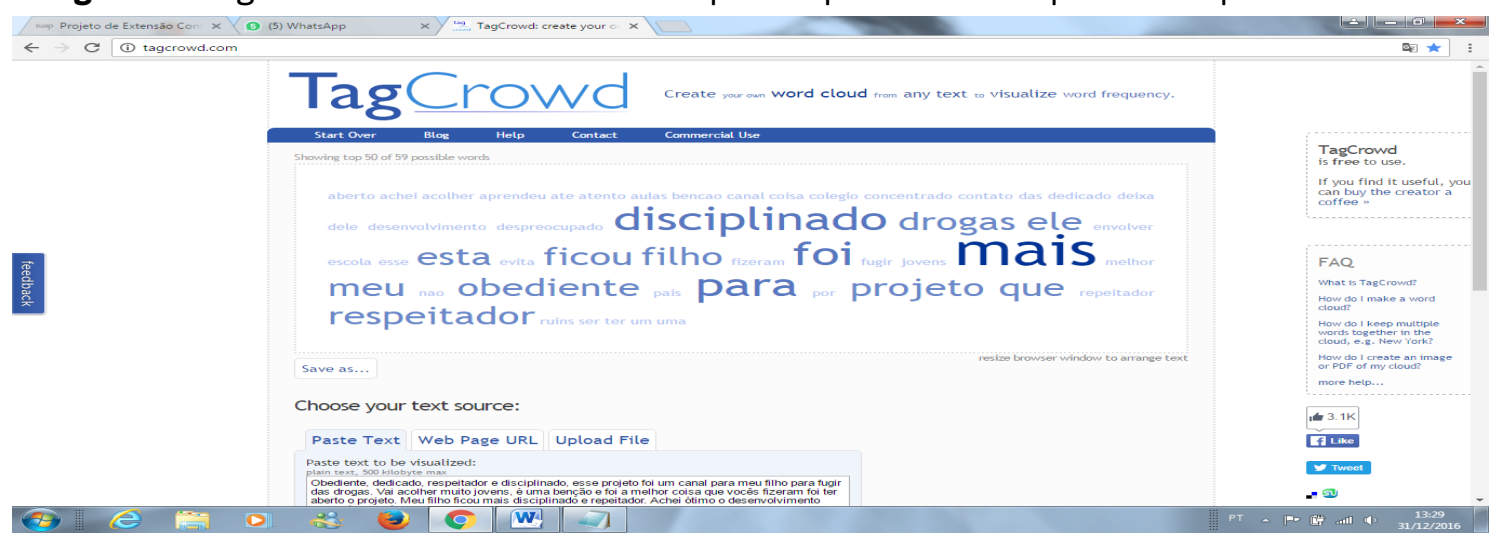

Fonte: Elaboração dos autores (2018).

A partir dos objetivos e resultados esperados no projeto, podemos considerar que sua execução proporcionou, ao final:

- O cumprimento do objetivo do projeto relativo à sensibilização de crianças e adolescentes através da prática educativa do Jiu Jitsu para a construção de uma consciência cidadã, além da elevação do status positivo desse esporte, desmistificando o paradigma historicamente construído de prática esportiva violenta para os alunos e seus pais. Essa sensibilização será reverberada nos diversos espaços sociais em que vivem os alunos, através de seus comportamentos (disciplina, obediência e respeito), além da inclusão social possibil- 
itada pelo projeto, uma vez que os alunos envolvidos são, em sua maioria, residentes em bairro que apresenta vulnerabilidade social;

- A efetivação da estratégia institucional do IFRN de inclusão social no dia a dia da escola;

- A participação de aluno do IFRN como bolsista na prática de Iniciação Científica, na qual o mesmo pode participar desde a criação do projeto ao acompanhamento, construção e aplicação das entrevistas com os atores desta proposta extensionista;

- A viabilização da prática educativa e sua constante adaptação aos saberes prévios dos alunos e seus pais, tendo sido conduzido de forma dialógica pelos professores voluntários de Jiu Jitsu, conforme proposto por Zabala (1998) e;

- A concretização da primeira graduação do aluno A. A. A, que foi realizada no dia 17 de dezembro de 2016, durante o encerramento do Projeto. Na ocasião, o aluno recebeu de um dos professores uma bolsa de financiamento para aprofundar seus treinamentos em uma academia privada de Natal/RN e sua inscrição para uma competição local (Grand Slam Nordeste de Jiu-Jitsu), realizada no período de 11 e 12 de fevereiro de 2017, em que o aluno se sagrou com o $3^{\circ}$ lugar na competição.

Os dados até aqui apresentados conferem ao Jiu Jitsu brasileiro a possibilidade de ser utilizado como uma estratégia de prática educativa crítico-emancipatória, que contribuiu para a construção da cidadania infanto-juvenil devido sua competência objetiva (educacional), competência social (cidadania, comportamento social) e competência comunicativa (integração social e conhecimento corporal).

\section{CONSIDERAÇÕES}

Considerando-se o objetivo do projeto sobre o processo de aprendizagem social, tem-se que: a aprendizagem dos alunos aferida continuamente, inclusive com a participação dos pais - não foi resultado da improvisação, pois os professores permitiram a adaptação do plano de aulas às necessidade dos alunos, o resgate dos conhecimentos prévios, a autoexplicação, ajudou os alunos a encontrarem sentido nos movimentos, ofereceu ajuda, elaborou atividades mentalmente estruturantes, criou ambientes para aprendizagem, tanto formais quanto não formais, favoreceu a autonomia etc., em consonância com o que coloca Zabala (1998).

O aprendizado construído na prática educativa do Projeto de Extensão descrito neste trabalho, seja formalmente (planejamento, avaliação, organização do local das aulas, estruturação de uma entrevista etc.), seja informalmente quando realizadas visitas a outras academias, quando construída uma campanha por redes sociais, quando um dos alunos ganhou uma bolsa devido ao seu desempenho, demonstrou a maturidade metodológica, educativa e sensibilizadora 
alcançada na condução do projeto por sua equipe de elaboração e execução, bem como nos resultados sociais alcançados pelos alunos quanto à construção de valores como disciplina, obediência e respeito, e o desenvolvimento de competências objetivas, sociais e comunicativas, importantes para uma sociedade democrática.

Além disso, o projeto "O Jiu Jitsu como prática educativa para a cidadania infanto-juvenil" trouxe várias inquietações para os atores envolvidos, bem como possibilitou a reflexão sobre diversas lições aprendidas, que poderão guiar futuras pesquisas sobre o assunto. Dentre elas, destacam-se:

- A importância do alinhamento entre o projeto com a política estratégica institucional de "Ampliar o acesso da comunidade ao CNAT", que propiciou a aceitação do projeto no Programa de Apoio Institucional à Extensão no IFRN;

- O aprendizado propiciado ao se conhecer outros projetos sociais e o trabalho de academias da cidade permitiu, à equipe do projeto, conhecer as limitações da ação e se preparar para os imprevistos. Para os alunos, foi importante para motivar e qualificar as técnicas do grupo;

- Discutir a proposta do projeto com os beneficiários permitiu o alinhamento entre suas necessidades com as possibilidades da equipe gestora do projeto;

- A mobilização de uma equipe comprometida permitiu a continuidade do projeto com flexibilidade diante das dificuldades do trabalho com voluntários, pois os professores se revezaram durante a execução do projeto, já que, concomitantemente, participavam de campeonatos, arbitravam competições e atuavam como professores em academias da cidade;

- A necessidade de inclusão de aporte financeiro para a continuidade da execução do projeto, pois para a graduação e a participação dos alunos em competições, é necessária a aquisição de quimonos e faixas. Sentiu-se a necessidade, para a concretização do próximo projeto, de subsídios financeiros para a obtenção desses materiais. No contexto do projeto executado, os quimonos utilizados provieram de doações de alunos de academias da cidade através dos professores voluntários, bem como da ação social de um dos professores, que arbitrou um evento em troca de quimonos para os alunos;

- As aulas do projeto, no subsolo do ginásio de esportes, dificultaram a visualização da ação pelos alunos que ficavam ociosos no campus após o treino de futebol, fato que pode ter comprometido a ampliação da turma;

- Percebeu-se que alguns alunos, ao longo do projeto, desistiram, pois preferiam acompanhar os treinos de futebol a participar do Jiu Jitsu. Alguns alegaram que viam no futebol uma perspectiva de melhoria de vida que ainda não enxergavam no Jiu Jitsu;

- $\quad$ Sentiu-se, com o andamento do projeto, a necessidade de melhor qualificação da ação social, pois alguns alunos tinham dificuldades de vir para os encontros, pois não tinham dinheiro para a passagem de ônibus ou vinham para o treinamento sem se alimentar, sendo este, também, um dos motivos da evasão. 
Quanto às limitações enxergadas no projeto, tem-se:

- Participação de poucas meninas no projeto;

- Limitação financeira para custear lanches, passagens de ônibus, material e participação dos alunos em competições;

- A necessidade de desenvolver estratégicas para agregar novos alunos e;

- Estabelecer horários e dias que evitem a concorrência entre a prática do Jiu Jitsu e os treinos de futebol no IFRN.

Diante do exposto, convém sinalizar que o projeto em tela, apesar das limitações vivenciadas, admitiu relevância na vida dos beneficiários, tendo em vista que os aproximou, sensibilizou e promoveu a aprendizagem sobre temáticas para a construção de uma consciência cidadã.

\section{REFERÊNCIAS}

ALVAREZ, F. de L.; MARQUES, J. C. Da marginalidade ao mainstream: reflexões sobre o MMA (Artes Marciais Mistas) e as sociedades capitalistas contemporâneas. E-Compós, v. 16, n. 3, p. 1-17, 2013.

ANDREATO et al. Brazilian Jiu-Jitsu simulated competition Part I: metabolic, hormonal, cellular damage, and heart rate responses. The Journal os Strength and Conditioning Research, v. 9, n. 29, p. 2538-2549, 2015.

ARRUDA, P. D. P.; SOUZA, B. J. de. Jiu-jitsu: uma abordagem metodológica relacionada à quebra de estereótipos. Redfoco, v. 1, n. 1, 2014.

BARROSO, A. L. R.; DARIDO, S. C. Escola, educação física e esporte: possibilidades pedagógicas. Revista Brasileira de Educação Física, Esporte, Lazer e Dança, v. 1, n. 4, p. 101-114, dez. 2006.

BRAGANÇA, B.; FERREIRA, L. A. G.; PONTELO, I. Práticas educativas e ambientes de aprendizagem escolar: relato de três experiências. Disponível em: <http://www.senept.cefetmg.br/galerias/Arquivos_senept/anais/terca_temal/ TerxaTema1Artigo17.pdf>. Acesso em: 6 maio 2017.

DA COSTA, L. Atlas do esporte no Brasil: Jiu jitsu. Rio de Janeiro: CONPEFE, 2006. Disponível em:<http://www.atlasesportebrasil.org.br/textos/75.pdf>. Acesso em: 6 maio 2016.

O ESTADO DE SÃO PAULO. Lutador de jiu jitsu é acusado de matar travesti e queimar corpo. Disponível em:

<http://sao-paulo.estadao.com.br/noticias/geral,lutador-de-jiu-jitsu-e-acusadode-matar-travesti-e-queimar-corpo-imp-,555791>. Acesso em: 6 maio 2016. 
GIRJ. Lutador de jiu-jitsu é preso no RJ por suspeita de assassinar a mulher. Disponível em: <http://g1.globo.com/rio-de-janeiro/noticia/2016/03/lutador-de-jiujitsu-e-preso-no-rj-por-suspeita-de-assassinar-mulher.html>. Acesso em: 6 maio 2016.

G1MS. Lutador de jiu-jitsu é preso suspeito de agredir aposentado a socos em MS. Disponível em: <http://g1.globo.com/mato-grosso-do-sul/noticia/2016/04/ lutador-de-jiu-jitsu-e-preso-suspeito-de-agressao-apos-brincadeira-em-ms. html>. Acesso em: 6 maio 2016.

IFRN. Função social. Disponível em: <http://portal.ifrn.edu.br/institucional/default-page>. Acesso em 6 maio 2016.

JONES, N. B.; LEDFORD, E. Força e acondicionamento para jiu-jitsu brasileiro. Strength and Conditioning Journal, vol. 34, n. 2, p. 60-69, 2012.

KOTLER, P. Administração de marketing: a edição do novo milênio. 10. ed. São Paulo: Prentice-Hall, 2000.

KUNZ, E. Transformação didático-pedagógica do esporte. 5. ed. Ijuí: Ed. Unijuí, 2003.

NEUENFELDT, D. J. (org). Saberes da educação física: construção a partir de experiências de pesquisa, ensino e extensão. Lajeado: Ed. UNIVATES, 2013.

PROJETO FRALDINHA. Disponível em: <http://portal.ifrn.edu.br/servidores/campus-verde/lateral/projeto-fraldinha/conheca-o-projeto/view>. Acesso em: 31 dez. 2016.

REIS, T. H. dos S.; SUZUKI, F. S.; GOMES, F. R. F. A utilização do jiu-jítsu brasileiro como conteúdo na Educação Física escolar. EFDeportes.com. Revista Digital. v. 17, n. 169, jun. 2012.

RUFINO, L. G. B.; MARTINS, J. C. O Jiu Jitsu brasileiro em extensão. Rev. Ciênc. Ext., v. 7, n. 2, p. 100, 2011.

2012.

A pedagogia das lutas: caminhos e possibilidades. [S. L.]: Paco Editorial:

TUBINO, M. J. G. Uma visão paradigmática das perspectivas do esporte para o início do século XXI. In: GEBARA, A. [et al.]; MOREIRA, W. W. (Org.). Educação física \& esportes: perspectivas para o século XXI. 9. ed. Campinas: Papirus, 2002, p. 125-139. 
VASQUES, D. G. As artes marciais mistas (MMA) como esporte moderno: entre a busca da excitação e a tolerância à violência. Esporte e Sociedade, v. 8, n. 22 , set., 2013.

ZABALA, A. A prática educativa: como ensinar. Porto Alegre: Artmed, 1998.

Data de recebimento: 05 de março de 2018.

Data de aceite para publicação: 22 de maio de 2018. 